\title{
La littérature des proscrits en Angleterre
}

$P$. Hamélius

\section{Citer ce document / Cite this document :}

Hamélius P. La littérature des proscrits en Angleterre. In: Revue belge de philologie et d'histoire, tome 1, fasc. 1, 1922. pp. 5967.

doi : 10.3406/rbph.1922.6155

http://www.persee.fr/doc/rbph_0035-0818_1922_num_1_1_6155

Document généré le 27/09/2015 


\section{La littérature des proscrits en Angleterre}

Deux poèmes anglais du XIV siècle idéalisant la vie des proscrits dans les bois nous ont été conservés. La critique littéraire se contente de signaler des points de contact entre eux, mais sans être jamais entrée dans le détail de leurs analogies et de leur's dissemblances. Leur influence sur les littératures modernes de l'Europe a cependant été assez grande pour mériter un examen attentif.

L'un d'eux, intitulé par son éditeur, Thomas Wright, le chant du proscrit de traillebaston, est en réalité, malgré sa forme lyrique. une satire contre une réforme judiciaire de la fin du règne du roi Edouard I'er d'Angleterre, l'ordonnance dite de traillebaston (1305). Ce dernier mot, dérivé du verbe ancien français trailler, c'est-à-dire traîner, haler (le mot flamand treilen signifie remorquer). désignait des rôdeur's armés de gourdins, des traîneurs de bâtons, qui, à la fin du règne d'Edouard $I^{\text {er }}$ et au début de celui d'lidouard II, semaient la terreur dans les campagnes anglaises, et se livraient à des excès contre la population paisible. Ils intimidaient témoins et jurés des cours de justice au point que leurs victimes étaient privées de la protection des lois. Ils paraissent d'ailleurs avoir joui de l'appui de certains grands seigneurs qu'ils aidaient à s'emparer de l'avoir des roturiers.

Pour porter remède à ces désordres, le parlement du printemps de 130 conféra au roi le pouvoir d'ordonner des 
enquêtes judiciaires par magistrats spéciaux dans les divers comtés, en vue d'exercer une répression énergique. Des malfaiteurs, le terme de traillebaston fut transféré d'abord à l'édit promulgué contre eux, ensuite à la juridiction extraordinaire instituée par l'édit. L'ordonnance ellemême, datée du 6 avril 130כ et imprimée dans son texte latin dans Rymer (Fordera, II, p. 960-961), est adressée à cinq officiers royaux. dont quatre sont nommés dans le poème; deux, Henri de Spigurnell et Roger Belflour (Rogerus de Balafaga dans Rymer) comme "gens de cruauté ", deux, Guillaume de Knoville et Guillaume Martyn, comme "gens de piété », qui prient pour le salut des pauvres.

L'édit décrit avec quelque détail la vie des proserits que la littérature anglaise devait glorifier pendant des siècles comme compagnons de Robin des Bois : "Vu que de nombreux malfaiteurs et perturbateur's de notre paix royale commettent de jour et de nuit homicides, brigandages, incendies et autres dommages, errent et vaguent par les bois. les pares et autres lieux divers, soit dans la banlieue, soit en dehors, dans les comtés de Cornouailles, Devon, Somerset, Dorset, Hereford, Worcester, Shropshire, Stafford, Wiltshire et Southampton et y reçoivent asile au très grand perril des gens qui traversent ces régions et de ceux qui les habitent, au mépris de notre autorité et au dommage évident de notre paix royale ", les nouveaux juges reçoivent l'ordre de rechercher les malfaiteur's, les gens qui les abritent, qui les soutiennent, qui leur prêtent mainforte el secours, qui les encouragent et dirigent dans leurs méfaits. Ils doivent, poursuivre aussi cenx qui composent pour de l'argent avec les criminels, qui les guident pour frapper, blesser, inaltraiter et tuer dans les foires et marchés, par haine, envie et malice, les sujets du rovaume, notamment ceux qui, étant appelés aux assises, au jury ou aux enquètes contre les méfaits, $y$ ont rendu leur verdict. Car ces criminels ont souvent. par leurs menaces, empêché les jurés de faire leur déclaration ou leur réquisitoire. Il faut rechercher aussi ceux qui font des paiements aux traillebastons. qui les nourrissent et les entretiennent, ceux qui les couvrent de leur puissance seigneuriale et qui 
se font leurs défenseurs, ceux qui extorquent de l'argent au moyen de menaces.

Par son énumération prolixe des crimes, délits et complicités qu'il dénonce, ce document législatif ressemble aux règlements de police affichés de nos jours sur les murs de la ville de Londres. Il permet par là même de se représenter la société anarchique où le vagabondage, le braconnage et la violence étaient encouragés et utilisés par les grands seigneurs, lavorisés par la corruption et les craintes des petites gens et subis lâchement par les marchands et les voyageurs. Le Robin des Bois des poètes a de même des alliés par'mi les nobles dont le rapproche sa naissance, et des protégés parmi les pauvres dont il partage la vie misériable. Quant aux commerçants, il leur accorde généreusement la vie sauve après avoir prélevé sur leurs richesses le tribut dî̀ à sa vaillance.

Cette sympathie pour les bandits, représentés comme des victimes des officiers royaux, soit évêques, soit vicomtes (e'est l'équivalent français du titre anglais de sheriff), éclate dans le poème conservé au manuscrit Harley 2253 du Musée britannique et publié par Thomas Wright : Le chant du proscrit de traillebaston ('). L'auteur du poème, écrit sous forme de monologue en dialecte anglonormand, la langue usuelle de la noblesse anglaise à cette époque, critique l'édit comme tyrannique. puisqu'il expose aux rigueurs de la loi le gentilhomme coupable seulement d'avoir infligé à son valet un châtiment bien mérité " d'une buffe ou de deux ". 'Tout en exceptant de ses récriminations la personne royale, il appelle la malédiction divine sur les auteur's de l'édit, qui d'après lui est fautif en plusieurs points. En menaçant des gentilshommes de prison, il fournit au vicomte (sheriff: un prétexte pour leur extorquer une rançon. Aussi le poète veut-il se tenir sous les joyeux ombrages, où la fausseté et la mauvaise foi sont inconnues, an bois de Beauregard, où vole le geai, où le rossignol chante tous les jours sans relâche Les méchants

(1) The Political Songs of England from the reign of John to that of Edward II. Londres 1839. - Une édition antérieurc, datie de 1818, est due à Francis Cohen, nommé plus tard Sir Francus Palgrave. Ayant collationni le: lexte de Wright avec le manuserit, je l'ai trouvi parfaitement fidèle. 
vauriens l'ont accusé de brigandage, au point qu'il ne trouve pas d'asile parmi ses amis. Quoiqu'il ait servi son sire le roi en paix et en guerre, en Flandre, en Écosse et en Gascogne, il se trouve sans ressources et toutes ses peines ont été en pure perte. Des menaces de vengeance contre les " jureurs " et les cruels à qui il veut briser l'échine et la croupe, les bras et les jambes, témoignent de l'humeur batailleuse du proscrit. Ils sont accusés de pousser au crime : " car par crainte de prison, maint homme se fera larron". Aussi marchands et moines devraient maudire les auteurs de l'édit; la protection royale ne saurait les préserver d'avoir à livrer leurs deniers. Tous les suspects sont invités à se joindre au proserit au vert bois de Beauregard, où il n'y a nul procès, sauf bêtes sauvages et joyeux ombrages, car le droit coutumier est trop redoutable. Mieux vaut vivre libre qu'être appelé devant les juges et souffrir la prison sous la garde de l'évêque. Qui n'est pas assez riche pour acquitter sa rançon sera livré à mort. Dieu seul peut protéger l'innocent poursuivi par l'envie, qui n'ose retourner dans sa propre terre. Il demande aux bonnes gens de prier pour lui, car il n'est pas homicide ni voleur de plein gré.

Le quatrain final sert d'envoi; sa tournure est ingénieuse :

Cest rym fust fet al bois desouz vn lorer,

La chaunte merle, russinole, e crye l'esperuer.

Escrit estoit en parchemyn pur mout remembrer.

Ft gitté en haut chemyn, qe vm le dust trouer. (1)

Tel est, eu abrégé, ce poème mêlè de convention littéraire et de ressentiments personnels, d'allusions politiques et de tableaux de la nature. Dans son essence, e'est un témoignage de la résistance des hommes de guerre, inclisciplinés et brutaux, aux lois protégeant contre leurs exactions les marchands et les gens d'église. La profession de fidélité au roi qu'ils ont servi à la guerre n'est qu'un

(1) Celte rime fut faite an bois, sous un laurier, Lì chantent le inerle et le rossignol et crie l'epervier; Elle est écrite sur parchemin pour mieux se retenir, Et jetée sur la grand'route pour quion l'y puisse trouver. 
masque transparent, où perce leur haine de l'ordre social et de ses gardiens. L'évocation du vert bois de Beaureward, avec ses ombrages riants, ses chants d'oiseaux et son gibier sauvage, relève la vie du proscrit par son charme poétique, mais sans l'empêcher de se comparer au sanglier des forêts :

Que ore vueille vivre come pork merra sa vye.

Pour l'histoire littéraire, ce poème n'est pas moins curieux que pour l'histoire sociale, car il annonce une longue série d'ouvres, comprenant les ballades anglaises en l'honneur de Robin Hood et de ses archers, datant des $\mathrm{Xv}^{\mathrm{e}}$ et $\mathrm{Xv}^{\mathrm{e}}{ }^{\mathrm{s}}$ siècles, des pièces de théâtre du règne d'Elisabetir et notamment la comédie de Shakespeare intitulée Comme il vous plaira (écrite probablement en 1699) et aboutissant à l'époque romantique à la glorification du bandit et du proserit. Il faut dater notre satire anglo-normande d'une époque proche de l'édit du $1 \%$ avril 1305 , puisque quatre des juges nommés dans l'édit y sont mentionnés et caractérisés. Dans ce cas, un siècle et demi la sépare des plus anciennes ballades de Robin des Bois, celle de Robin Hood et du Moine, celle de Robin et de Gandaleyn, conservées dans des manuscrits de 1450 environ. Dans l'intervalle se place un autre poème de proscrit, le conte de Gamelyn, qu'on s'accorde à placer vers 1350 . Ce conte s'écarte sur plus d'un point de la satire que nous venons de résumer : sa forme est, nou didactique ou lyrique, mais narrative, sa langue est le moyen-anglais, non l'anglo-normand, son accent est plus vulgaire, plus grossier, moins influencé que la satire par la poésie courtoise. Mais le fond de sentiments et d'idées y est le même, ou à peu prèș.

La vie vagabonde du braconnier au sein des bois n'y est nullement idéalisée : le vieil Adam, le "despensier " ou chef d'office de la noble famille de Gamelyn, jure par Saint-Richier qu' "il vaut mieux porter les clefs qu'errer au bois sauvage et $y$ déchirer ses habits " (vers 621-622). Les oiseaux n'y chantent pas, la verdure n'y réjouit pas le cour. Les plaisirs de la chasse n'y figurent pas davantage. ". Il faut bien aller au bois quand on ne peut rester en 
ville ", avoue le jeune Gamelyn en réponse à un questionneur. "Si nous rencontrons un chevreuil, nous tirons dessus, comme gens affamés et sans nourriture, qui sont en mauvais point sous les tilleuls des bocages " (v. 672-676). Nous voilà loin de la poésie forestière des ballades de Robin Hood et des scènes pastorales de Shakespeare.

En retour, la même haine pour les gens de justice remplit le conte de Gamelyn et la satire de traillebaston. Juges, jurés et vicomtes, tous les officiers du roi y sont battus et injuriés par Gamelyn, qu'ils ont lié, condamné et tenu en prison. Dans l'épisode final, le proserit s'installe au banc du tribunal, fait comparaître vicomte. juges et assesseurs, et ordonne de les pendre haut et court. Cette rancune contre les serviteurs de la loi n'empêche du reste pas la réconciliation entre le proscrit et son souverain : il est admis à faire sa pajx, il est même nommé " chef juge de la franche forêt " pour le venger des avanies que lui ont fait subir les gens de la loi. Un autre point oì le conte de Gamelyn concorde avec la satire de traillebaston est l'aversion pour les gens d'église. et surtout pour les prélats. Ils sont roués de coups et bafoués dans le conte, où par des plaisanteries assez lourdes on ne leur laisse passer la porte qu'après leur avoir administré le sacrement de l'ordre et leur avoir donné l'absolution à coups de gourdin (v. 333); l'on y recommande aussi de ne pas verser le sang des hommes de Sainte Eglise, mais de leur rompre bras et jambes (v. j16-ว24). Dans la satire de traillebaston, c'est l'évêque qui garde dans ses cachots les proscrits prisonniers (p. 234). Tous ces détenteurs de l'autorité judiciaire sont du reste dépeints comme des fauteurs d'injustice el des oppresseurs. Par leurs persécutions et leurs voleries ils chassent dans les bois et réduisent à une vie de rapine des hommes de race noble, d'âme généreuse et de coeur pieux, qui deviennent malgré eux larrons et meurtriers, et qui n'ont d'autre désir que de se réconcilier avec leur légitime souverain et de reprendre leur rang dans la société féodale. Le guerrier anglo-normand du règne d'Edouard Ier et d'Edouard II a toute raison de se soustraire par la fuite aux duretés du droit coutumier, aux exactions des vicomtes et aux prisons épiscopales; Gamelyn ne 
réclane que son héritage paternel, et n'est que trop accommodant envers son frère aîné tyrannique et rapace.

Les vertus distinctives des proscrits poétisés sont le courage et la force physique. Dans le conte de Gamelyn et dans les scènes de Shakespeare qui en sont tirées, le héros n'atteint à ses fins que par la vigueur musculaire. Son grand triomphe est une partie de lutte où il casse les côtes à un champion insolent et orgueilleux, soudoyé pour le supprimer. Vis-à-vis de la ruse, il reste naïf et désarmé. Il incarne déjà le type conventionnel très britannique du grand cœur simple et droit, servi par une volonté ferme et une musculature puissante. Mais les critiques anglais font fausse route en voulant $y$ reconnaître une création de la muse populaire ou un idéal démocratique. Sa confiance en son courage tet en son adresse procède de la tradition militaire des féodaux, tout comme l'orgueil de sa naissance noble. Ses sentiments et son genre de vie sont ceux d'un aristocrate et d'un guerrier; on pourrait ajouter d'un sportsman, si l'on ne craignait de verser dans le modernisme.

Jamais les légendes de proscrits ne se sont départies de leurs tendances nobiliaires et féodales : le bandit $y$ est jours bien né, habile aux armes de guerre et de chasse (l'arc est son arme favorite dès la satire de traillebaston et le restera). Il est vaillant et loyal, et ses victimes, marchands et moines, n'ont guère lieu de se plaindre, car ils ne sont dépouillés que de leur superflu et ils méritent les coups par leur bassesse. Les ouvres poétiques consacrées aux proscrits convrent d'un voile discret leurs actes de brigandage et se contentent de ridiculiser leurs trop riches victimes. Ise jeune héros Gamelyn pille arec ses amis la cave et le garde-manger de son frère dénaturé, mais c'est en légitimes représailles des extorsions et des injustices qu'il a subies avec la complicité des légistes et des ecclésiastiques.

L'étude de toute cette vaste branche de la littérature anglaise a été dominée par des préjugés qui en faussaient les conclusions. Les ballades de Robin Hood, dont aucune ne remonte au delà du $x^{\text {e }}$ siècle, ont été arbitrairement attribuées à une antiquité reculée. En y cherchant l'ex- 
pression de sentiments populaires, on a voulu $y$ trouver une protestation des anciens habitants germaniques, descendants des Anglo-Saxons, contre la Conquête normande et la tyrannie des nobles de langue frauçaise. Ces théories aventureuses, inspirées par la passion nationaliste et dépourvues de toute base documentaire, sont abandonnées de jour en jour. Une savante américaine, $M^{\text {me }}$ Louise Pound, vient de leur porter un nouveau coup dans un livre récemment paru sous le titre : Poetic Origins and the Ballads (1921), où elle démontre l'influence de la poésie religieuse sur les ballades séculières. Malgré la sûreté de sa méthode, nous croyons que certains aspects de la question lui ont échappé et qu'il est possible de pousser plus avant l'étude des sources de la légende de Robin Hood. Qu'il nous suffise, pour aujourd'hui, d'avoir précisé les relations entre le Chant du proscrit de traillebaston et le conte de Gamelyn.

Si nos conclusions sont correctes, nuus goûterons pentêtre un peu mieux la poésie bocagère de la Forêt d'Ardenne, dont la fraîcheur et le charme fonţaimer la comédie sentimentale Comme il vous plaira, de Shakespeare, la robuste naïveté de son héros Orlando, le vainqueur de la lutte, ses scènes de chasse et son tableau des joies du forestier. Nous y trouverons un écho éloigné du poème de traillebaston, de son éloge du vert bois, de ses chants d'oiseau, dans la chanson qui flatte la mélancolie de Jacques, le banni pensif et délicat :
Under the greenwood tree
Who loves to lie with ine
And turn his merry note
Unto the sweet bird's throat,
Come hither, come hither, come hither,
Here shall he see no enemy,
But Winter and rough weather.

Quant aux romantiques français, ils ont connu tout d'abord Robin des Bois par l'Ivanhoë de Walter Scott (1819) et par un roman de Thomas Love Peacock, intitulé Maid Marian (1822), traduit en français par $M^{\text {me }}$ Daring. sons le titre de Robin Hood on la Forèt de Sherwood, roman historique (1826). Un autre livre témoignant de 
l'enthousiasme qu'excitait sous la Restauration la littérature des proscrits est un recueil des ballades imprimé à Paris en langue anglaise chez Renouard (1825). La préface en est signée par un publiciste d'origine allemande, LoèveVeimars. En 1830, Victor Hugo fit retentir au Théâtre Français le cor de chasse d'Hernani, écho des sonneries des forêts de Sherwood et de Nottingham, et mit sur les planches son proscrit espagnol, couvert du froc de moine dont s'étaient affublés les archers, compagnons du proserit anglais.

Paui hamélius. 